\title{
ETOs and biodiversity \\ A right to food perspective on the intersection of human rights and environmental law
}

\author{
Philip Seufert and Sofía Monsalve Suárez
}

\section{Introduction}

The rapid and dramatic loss of biodiversity is one key manifestation of the deep ecological crisis that humanity and the planet are currently facing, the other key issue being global warming. Several scholars and activists have pointed out that the world is currently facing a new mass extinction - the sixth in the history of planet Earth, this time caused by us, humans. The rapid destruction of biodiversity affects the lives and livelihoods of people all over the world and has direct consequences on the enjoyment of human rights. The emergence of the novel coronavirus SARS-CoV-2 in 2020 has forced us once more to critically consider our societal relationship with nature.

On the following pages, we will discuss the close interrelatedness between biodiversity and the realization of human rights, focusing particularly on the extraterritorial component of states' obligations in this regard. We will identify some areas that are critical to addressing both human rights violations and ecosystem destruction and line out ways in which states are required to act in order to comply with their obligations under international human rights and environmental law. Our analysis and proposals are based on our work as human rights practitioners and, in particular, our close work with rural people and their organizations, especially organizations of small-scale food producers and indigenous peoples.

\section{Biodiversity and human rights: A multifaceted relationship that stretches beyond borders}

Biodiversity and human rights are closely interrelated. Firstly, biodiversity and functioning ecosystems are necessary to realize a number of human rights, such as the rights to food, water, health and culture (Knox 2017). Food production and the availability of nutritious, healthy and culturally adequate food fundamentally depend on functioning, biodiverse ecosystems as well as humans' ability to live in concert with other living beings - plants, animals, insects and microorganisms. Biodiversity is also a critical component of natural water cycles as well as the access 
to safe water for consumption, food production and other household uses. For the billions of people who directly depend on the cultivation and harvesting of food and other natural materials, the diversity of living nature is the basis for their right to work. Healthy ecosystems prevent pathogens and dangerous diseases to spill over to humans. In addition, millions of plants, animals and microorganisms are the basis for drugs and treatments that ensure physical and mental health and wellbeing. Finally, ecosystems, animals, plants and all of living nature are the basis of many forms of cultural expressions and spiritual life that people and communities celebrate around the world.

While biodiversity and healthy ecosystems are essential for the survival and wellbeing of all people, they are particularly important for all those people and communities who live in close relationship with living nature, such as indigenous peoples, peasants, pastoralists, artisanal fishers and forest dwellers. For these groups, the natural environment is not only the basis of their livelihoods, but also the source of their dignity and self-determination. A second crucial aspect of the intersection between human rights and biological diversity therefore is the respect, protection and fulfilment of the rights of these people, as a precondition to ensure the preservation of biodiversity and functioning ecosystems. This understanding has consistently evolved over the last years and has led to an increased recognition that the protection of our living environment is not mainly an issue of conservation, but that communities and people play critical roles as custodians and stewards of ecosystems (Boyd 2020). What is more, conservationist approaches that are based on the assumption that nature and biodiversity can only be protected if humans are excluded, have led to the expulsion of rural communities and indigenous peoples from their lands and territories in many parts of the world (Tauli-Corpuz 2016).

This two-way relationship between human rights and biodiversity relates to states' obligations under international law, both within their national territory and beyond borders. Indeed, whereas the preservation of biodiversity and the management of ecosystems have a strong local component - e.g. local communities managing a given landscape or forest - they are also fundamentally transnational issues. As the former UN Special Rapporteur on human rights and the environment has noted, 'many of the components of biodiversity, the threats to biodiversity and the benefits biodiversity provides have transboundary or global dimensions' (Knox 2017). For instance, many ecosystems, such as not only oceans, rivers or lakes, but also terrestrial ecosystems, are transboundary. Moreover, however local their management may be, ecosystems and landscapes are linked regionally as well as globally. One example are migratory birds who connect ecosystems across continents. In addition, the destruction of ecosystems that are relevant for the entire planet, such as the deforestation of the Amazon rainforest or the dying of coral reefs, affect people all around the world. Finally, several of the key drivers of ecosystem destruction and biodiversity loss need to be understood and addressed as transnational issues.

\section{Factors of biodiversity loss and related human rights violations}

Based on FIAN's documentation of violations of the human right to food and nutrition around the world for more than 30 years, we have identified a number of factors leading to the destruction of biodiversity and adverse human rights impacts. The emerging patterns are confirmed and complemented by the findings of human rights bodies and authoritative scientific evidence regarding the drivers of biodiversity loss (IPBES 2019). It should be stressed that biodiversity loss/destruction is one aspect of broader environmental harm or degradation, and is often linked to other forms thereof (e.g. pollution through toxic substances, soil degradation, etc.).

Among the first factors causing biodiversity loss and human rights violations are deforestation and the destruction of land and water ecosystems for the expansion of industrial agriculture, 
in particular monoculture plantations of globally traded cash crops such as soy, sugar cane, maize etc. Conversion of forests, grasslands and arable land as well as destruction of water bodies also occur in the context of industrial/extractive projects, such as mining, oil and gas extraction, manufacturing, etc. All these activities cause major destruction of ecosystems and, in many cases, displace local communities and people. They further lead to significant pollution of water, soils and air, including through the use of pesticides, industrial runoff, emissions etc., which negatively affect biodiversity and lead to the impairment of human rights (FIAN et al. 2018). In the context of marine ecosystems, industrial fishing and intensive aquaculture are main factors leading to overexploitation, pollution and the destruction of biodiversity, while negatively affecting small-scale fishers, fish harvesters and fish workers (Ertör and Ortega-Cerdà 2018). ETO issues arise through the involvement of transnationally operating corporations in extractive activities, their financing and/or the trade of raw materials and products resulting from such activities. In addition, ETOs arise in the context of state policies (e.g. in the field of food, energy, trade and finance) that promote such activities in other countries.

Another important driver of the destruction of land and water ecosystems as well as the loss of land, fisheries and forests are large-scale infrastructure projects, such as dams, highways, large ports and real estate development. In several cases, such projects are part of broader policies aiming at establishing special economic zones to boost economic development (Guttal and Chrek 2016). ETOs become relevant in cases where such projects affect other countries (e.g. dams on transboundary rivers), and whenever foreign public or private actors are involved in the financing and/or implementing of such activities, including international/regional development banks, development cooperation or companies involved in construction.

Biological diversity, in particular agricultural biodiversity, is also reduced through the promotion of a limited number of homogeneous and uniform crops and varieties through agricultural policies, in particular a push for industrial, hybrid seeds of a limited number of high-yielding crops, as well as genetically modified organisms (GMOs). According to the UN Food and Agriculture Organization (FAO), this has led to the loss of some 75 percent of plant genetic diversity over the last century (FAO 2005). Genetically uniform industrial varieties and GMOs cannot be adapted by peasants and indigenous peoples to changing climatic and environmental conditions. In this context, human rights and ETO issues arise, among others, because of development cooperation and/or the expansion of intellectual property rights (IPR) regimes (e.g. through trade agreements), which limit the use and conservation of seeds, as well as their adaption by peasants and indigenous peoples to the local environment (De Schutter 2009). In addition, the global industrial seed and agricultural input market is dominated by a few transnational corporations whose operations directly impact biodiversity and peasants' and indigenous peoples' rights over seeds around the world.

It must further be noted that there is a close relationship between the rapid loss of biodiversity and global warming. Climate change, rising average temperatures and changing rainfall patterns strongly affect biodiversity. In parallel, declining biological diversity reduces the resilience and adaptability of ecosystems to changing climatic conditions, and, consequently, of societies in general. This results in adverse impacts on the right to food and nutrition as well as other human rights. A clear example that shows the interlinkages between biodiversity loss and climate change is deforestation, which is a critical factor of biodiversity loss, while also being an important driver of global warming. Consequently, states' ETOs in the context of climate change are also highly relevant in the context of biodiversity (refer to chapter on climate change in this volume).

Importantly, women (in particular rural women) and other gender groups are particularly affected by the destruction of ecosystems and biodiversity and its impacts on communities' and 
families' livelihoods. These often add to existing structural discrimination and marginalization. In many countries and regions, rural women play an important role as custodians of biodiversity, conserving a vast array of species, breeds and varieties (both domesticated and wild), including when these are no longer used to generate income. Another group that is particularly affected in the context of ecosystem destruction are human rights defenders working on land and environmental issues (EHRDs) who are the target of different forms of violence (Global Witness 2020). EHRDs often operate in remote areas and thus have more difficult access to protection mechanisms and justice. In many instances, they are members of already marginalized groups, including ethnic minorities. Individuals and communities opposing ecosystem destruction also frequently face risks linked to the existence of significant power imbalances. States' ETOs in the context of human rights and biodiversity therefore require them to take into account the impacts on women and EHRDs in the contexts mentioned above.

What this list of key factors of biodiversity destruction and related human rights violations shows is that states' obligations related to biodiversity, and specifically their ETOs, require them to take action in a range of policy fields, including:

- $\quad$ Food and nutrition;

- Seeds and biotechnologies;

- Development cooperation, including in the context of environmental protection and governance of land and natural resources;

- Trade, investment and finance, including corporate accountability;

- Energy;

- Climate change;

- Protection of human rights defenders;

- Women's rights and gender equality.

\section{States' ETOs related to biodiversity}

As said before, biodiversity has a clear transboundary and global dimension, regarding its components, the factors that drive its loss and the benefits that arise from it. Therefore, the impacts that states' acts and omissions may have beyond their national territories require special attention in the context of their obligations under international law. As the previous section has shown, states' ETOs are relevant to address the rampant destruction of biodiversity through economic activities and to protect affected people. In addition, ETOs require states to cooperate in order to support the realization of human rights and the preservation of biodiversity and ecosystems. This section will develop further on states' ETOs in this context, building on the general and specific obligations of states under human rights law as well as the way these have been summarized and clarified in the Maastricht Principles (MP).

\section{Obligation to respect}

In general terms, states are required to respect, protect and fulfil human rights as well as apply the principles of non-discrimination, non-retrogression and accountability. In the context of ETOs, this requires states, firstly, to respect human rights by avoiding to cause harm in other countries. This means that they must take measures to prevent their acts and omissions, including their policies and laws, from directly or indirectly interfering with the enjoyment of human rights and from contributing to biodiversity loss (MP 13, 20 and 21). Direct interference refers to the involvement of public entities in contributing to biodiversity-related human rights violations. 
One example is development cooperation policies or programs supporting conservation initiatives that result in the dispossession of indigenous peoples or other rural people. Also the support of land policies in other countries, which focus on the promotion of land-based investments may lead to dispossession and ecosystem destruction, especially when there are no adequate safeguards in place. Another example is the public financing of infrastructure projects in other countries, e.g. through (national, regional or international) development banks.

Indirect interference encompasses conduct that reduces the ability of another state to comply with its human rights obligations. This can occur through trade and investment agreements, which reduce the policy space of states to implement measures required to ensure the preservation of biodiversity and ecosystems. A critical issue in the context of biodiversity are provisions requiring the establishment or tightening of IPR regimes, which are frequently part of trade agreements and limit farming communities' rights to conserve, use, exchange and sell seeds (Berne Declaration 2014). This example points to possible tensions with other international agreements, for instance, in the framework of the World Trade Organization's (WTO) Agreement on Trade-Related Aspects of Intellectual Property Rights (TRIPS) or the World Intellectual Property Organization (WIPO). In such cases, the principle of the primacy of human rights as well as the special attention that needs to be given to vulnerable and marginalized groups must guide states to prioritize their human rights obligations.

One important procedural element of avoiding harm in other countries is to conduct prior human rights, social and environmental impact assessments as well as to monitor the extraterritorial impacts of policies, laws and practices where the risk of adverse impacts on human rights and biodiversity is high (MP 14). States are thus required to carry out ex ante assessments and to put in place monitoring mechanisms in the context of their policies in the above-mentioned policy fields. It is of crucial importance that prior assessments are conducted by an independent body and with public participation, and their results be made public. Monitoring of existing policies should focus on human rights compliance and involve independent human rights bodies/experts (including national human rights institutes in affected countries) as well as those affected by policies. The outcomes of prior and ex post assessments need to inform measures to prevent, cease and remedy harm.

\section{Obligations in the context of international agreements and cooperation}

The duty to avoid harm also requires states to elaborate, interpret and apply international agreements in a manner consistent with their human rights obligations (MP 17). This includes agreements in the area of environmental protection and conservation, food, trade, investment, finance, development cooperation and climate change. In the context of biodiversity, this also refers to the need to comply with states' obligations under international environmental law, specifically the Convention on Biological Diversity (CBD) and its protocols as well as the International Treaty on Plant Genetic Resources for Food and Agriculture (ITPGRFA). These agreements further need to be implemented according to the highest human rights standards and based on the principle of the primacy of human rights. This requires states, among others, to rigorously apply the precautionary principle in the context of GMOs and biotechnologies. It also requires them to support the implementation of peasants' and indigenous peoples' rights over seeds, as recognized by the ITPGRFA, and to refrain from interpreting these rights in a manner that restricts them to the benefit of IPR. This duty is also relevant in the context of the establishment of market-based mitigation and offsetting schemes under international environmental and climate agreements (sometimes subsumed under the term 'nature-based solutions'). Such schemes 
usually have transboundary or extraterritorial components (e.g. because restoration measures in one country can be used to compensate for ecosystem destruction in another state) and entail risks of dispossessing local people as well as aggravating ecosystem destruction and biodiversity loss (African Centre for Biodiversity 2020).

The UN Special Rapporteurs on human rights and the environment have emphasized the need for cooperation between states in the context of biodiversity, stating that while international cooperation normally plays only a supporting role in the protection of human rights, [...] the effective protection of biodiversity, like the effective mitigation of climate change, is possible only with international cooperation' (Knox 2017, para. 36). This resonates with MP 29 and 32, which clarify states' obligation to participate in good faith in international governance processes in order to create a conducive environment for the universal realization of human rights, as well as to ensure that their policies and practices respect human rights principles and priorities when engaging in international cooperation. The latter includes prioritizing the rights of marginalized and disadvantaged population groups, observing the right to participation and self-determination, as well as the principles of non-discrimination and equality, including gender equality, and avoiding retrogressive measures. These obligations require states to ensure that their positions in international negotiations and policy spaces are in line with their human rights obligations as well as their commitments under environmental law, especially in those areas that entail risks of causing or facilitating ecosystem destruction and biodiversity loss (see list of policy issues above). Whereas the duty to cooperate applies to all countries, the Special Rapporteur on human rights and the environment has pointed out that wealthy states in particular must "contribute their fair share towards the costs of conserving, protecting and restoring healthy ecosystems and biodiversity in low-income countries, in accordance with the principle of common but differentiated responsibilities' (Boyd 2020, para. 74).

\section{Obligation to protect}

Regarding their protect obligations, states' ETOs require them to establish the necessary regulatory mechanisms to ensure that non-state actors that they are in a position to regulate do not impair the enjoyment of human rights in other countries (MP 24). This means concretely that states must adopt and enforce measures to protect human rights and biodiversity from harm caused by transnationally operating corporations, wherever a corporation has its centre of activity, is registered or domiciled or has its main place of business or substantial business activities, in the state concerned. As has been described in the previous section, corporate activities related to industrial agriculture, intensive aquaculture, mining, infrastructure development, energy production, etc. are the main drivers of biodiversity loss and related human rights violations, and often the harm is caused in other countries than corporations' home states. Rural people such as peasants, indigenous peoples, artisanal fishers, pastoralists, forest dwellers and rural workers are particularly affected by ecosystem destruction and human rights violations resulting from such activities. Special attention needs to be put on the biodiversity and human rights harm caused by toxic substances, such as pesticides. Another relevant example are transnational seed companies that use aggressive marketing practices and their economic power to impose the use of industrial/commercial seeds and GMOs on rural people, thus undermining local seed and peasant seed systems, which are crucial for the conservation of agricultural biodiversity and the realization of the right to food and nutrition (Global Network for the Right to Food and Nutrition/ Global Convergence of Land and Water Struggles - West Africa 2017).

Another way in which corporations impair rural people's rights over seeds, breeds and other genetic resources is related to the use of digital technologies. Technological developments of the 
last decades allow the sequencing of genetic material and its storing in digital format in huge data bases (in policy debates, this is often referred to as digital sequence information, or DSI). Biotechnologies, such as gene editing, allow introducing the respective traits into the genome in order to create varieties with desired characteristics (e.g. resistance to drought). In combination with intellectual property rights in the form of patents on genetic sequences, digitalization further restricts the rights of peasants and indigenous peoples over seeds and biodiversity, even though most of the genetic material that forms the basis of digital sequencing has been collected in their fields and they detain the associated traditional knowledge. DSI and patents are also likely to further increase the concentration of the industrial seed sector, which is currently dominated by four companies (ETC Group 2019). These examples point to the fact that effective measures to regulate transnationally operating corporate actors and hold them to account need to be a critical element of states' efforts to preserve biodiversity and ensure its sustainable use. Such regulation is particularly important in the light of the high level of concentration in the industrial seed and agricultural input sector.

As part of their ETOs, states must, moreover, cooperate in regulating and holding TNCs and other non-state actors accountable for human rights abuses and ensuring effective remedies for those affected (MP 27). This is particularly important in the context of the increasing financialization of the economy, which entails, among others, complex financing schemes - 'investment webs' - of extractive activities, involving many different actors (companies directly involved in the operations as well as different forms of financers, such as shareholders, banks, investment funds, pension funds etc.). Such investment webs typically stretch over different countries, implying finance flows across borders (FIAN et al. 2020). It is therefore important to stress that measures to regulate corporate actors need to include the legal duty on parent companies to exercise due diligence by controlling their subsidies, as well as addressing involved actors throughout investment webs.

In addition to corporations, the Special Rapporteur on Human Rights and the Environment has pointed out to the role that conservation organizations play in the context of biodiversity, including in the context of human rights impairments and violence through exclusive conservation activities (Boyd 2020, paras. 78-79). In the context of their protect obligations, states must therefore also monitor and regulate the activities of conservation organizations that they are in a position to regulate as well as conditioning financial support to such organizations to effective respect of human rights.

As mentioned above, EHRDs are among the groups that are particularly at risk of human rights impairments in the context of biodiversity and ecosystem destruction. States therefore need to put a particular emphasis on ensuring their protection - especially in cases where actors are involved that they are in a position to regulate - and are required to cooperate with other countries in this regard, including through diplomacy.

\section{Obligation to ensure effective remedy}

States' ETOs require them further to put in place effective accountability mechanisms to ensure that individuals and communities affected by human rights violations related to biodiversity loss and ecosystem destruction have access to effective remedies, including judicial remedies where necessary (MP 37 and 38). Important components of this duty are to cooperate with other states to this effect (MP 27) - in particular those states where the harm has been caused - and to ensure remedies in cases of impairments caused by the transnational operations of corporations or conservation groups. Given that moral-duty-based and non-judicial grievance mechanisms have in many cases proven to be ineffective in addressing human rights abuses, 
state-based judicial remedy is crucial and human rights obligations call for states to advance their judicial system, opening it up and guaranteeing full access to civil, administrative and criminal effective justice systems to all victims of corporate human rights abuses, wherever they occur, including in the context of biodiversity and ecosystem destruction. As emphasized before, states should also take specific measures to ensure the protection of EHRDs, which includes ensuring effective remedy in cases of human rights impairments.

\section{Bringing together human rights and environmental law}

The description of states' ETOs in the context of biodiversity and human rights in the previous section is based on an integrated reading of states' obligations under international human rights law on the one hand, and international environmental law on the other. Both fields of law provide critical procedural and normative guidance for states, but have historically developed on separate tracks - though not entirely disconnected. The understanding of their close interrelatedness has advanced only recently and is still in the building. This applies to the interconnection of biodiversity and human rights in general as well as in particular their implications for ETOs. Indeed, the extraterritorial component of states obligations at the intersection of biodiversity and human rights is a field that requires further attention.

\section{Human rights}

Regarding human rights, it is worth noting that the Universal Declaration on Human Rights as well as the two human rights Covenants are largely silent on nature and biodiversity, with the exception of Articles 1.2 of both the International Covenant on Civil and political Rights and the International Covenant on Economic, Social and Cultural Rights, which establish the principle that peoples have sovereignty over their natural resources. They do not, however, explicitly address the relationship between nature and human dignity as a core objective of human rights. However, the fact that the realization of several of the rights enshrined in these documents require biological diversity and functioning ecosystems has been recognized by some of the General Comments (GCs) issued by the Committee on Economic, Social and Cultural Rights, in particular GCs 4, 12, 15 and 21. The Committee on the Elimination of Discrimination Against Women's General Recommendation no. 34 on the rights of rural women is more explicit about biodiversity, underlining states' obligations to address threats posed by loss of biodiversity (para. 12) and clarifying that seeds and land are fundamental human rights (para. 56). It should be noted that all these documents also refer to ETOs (sometimes referred to as 'international obligations'), but without going into detail regarding the biodiversity-related components. Based on the discussion in the previous chapter, it is noteworthy that GC 24 on state obligations in the context of business activities refers to environmental impacts of such activities and contains comprehensive guidance on states' ETOs related to the regulation and monitoring of transnational corporations.

In recent years, the Human Rights Council's universal periodic review process as well as the treaty bodies have been increasingly highlighting the human rights impacts of damage to ecosystems and biodiversity, in particular in the context of deforestation and economic activities (Boyd 2020, paras. 62-63). It should be noted, however, that the observations and recommendations issued so far do not explicitly refer to extraterritorial aspects in this regard.

Human rights that are closely tied to biodiversity are also enshrined in regional human rights agreements, including the African Charter on Human and Peoples' Rights as well as the American Convention on Human Rights and its Additional Protocol in the Area of Economic, 
Social and Cultural Rights (Protocol of San Salvador). The latter also explicitly recognizes the right to a healthy environment (art. 11), which is also enshrined in several national legislations. Additional regional agreements that are important in the context of human rights and biodiversity are the Regional Agreement on Access to Information, Public Participation and Justice in Environmental Matters in Latin America and the Caribbean ('Escazú agreement') as well as the Aarhus Convention. None of these instruments, however, is very explicit about the extraterritorial components of these rights.

\section{Environmental law}

Regarding international environmental law, the most important reference in the context of biodiversity is the CBD, which was adopted during the 1992 United Nations Conference. It is worth noting that the CBD does not focus on environmental rights of people or communities, but rather on the way in which states must ensure the conservation and sustainable use of biodiversity that are present in their national territories as well as the use of such biological resources by other countries. However, it recognizes certain rights of indigenous peoples and local communities and states' obligations in this regard, namely to respect, preserve and maintain knowledge, innovations and practices of indigenous and local communities relevant for the conservation and sustainable use of biological diversity (art. 8(j)), as well as to protect and encourage customary use of biological resources in accordance with traditional cultural practices (art. 10(c)). Article 5 underlines the importance of cooperation in the context of biodiversity conservation and article 22 clarifies that obligations under other international agreements need to be implemented in a way that does not damage biodiversity.

The CBD has two protocols that provide further normative guidance. Firstly, the Nagoya Protocol establishes that states must take measures to ensure that traditional knowledge associated with genetic resources that is held by rural people and communities is accessed with their prior and informed consent or approval and involvement, and that mutually agreed terms have been established (art. 7). In addition, states are required to respect indigenous and local communities' customary laws with respect to traditional knowledge associated with genetic resources, and to not restrict the customary use and exchange of genetic resources and associated traditional knowledge within and amongst indigenous and local communities (art. 12). Secondly, the Cartagena Protocol is the main international agreement on biosafety for GMOs and further specifies states' obligation under the CBD to implement measures to regulate, manage and control the risks associated with the use and release of living modified organisms resulting from biotechnology (art. 8(g)). The Cartagena Protocol reaffirms the precautionary principle as one of the cornerstones of environmental laws (art. 1) and contains provisions regarding the transboundary movement, transit, handling and use of GMOs, as well as guidance on risk assessments, monitoring and safeguards for the environment and human health (Annex III, art. 4). The CBD's emphasis on states' international obligations apply also to both protocols, in particular where access to genetic resources involves actors from more than one country, as well as in the context of transboundary movement of GMOs.

Building on the CBD, the ITPGRFA recognizes the rights of peasants and indigenous peoples over seeds. It recognizes the access to and use of plant genetic resources for food and agriculture as key elements of food security. A key element of the treaty is the recognition of peasants' and indigenous peoples' rights over seeds, based on the recognition of their past, present and future contribution to the preservation and sustainable use of plant genetic resources (preamble). In article 9, the Parties recognize these rights (referred to as 'farmers' rights'), including their rights to the protection of traditional knowledge relevant to plant genetic resources 
for food and agriculture; the right of peasants to equitably participate in sharing benefits arising from the utilization of plant genetic resources for food and agriculture; and their right to participate in making decisions on matters related to the conservation and sustainable use of plant genetic resources for food and agriculture (art. 9). It further stresses that Parties shall not limit peasants' and indigenous peoples' rights to save, use, exchange and sell farm-saved seed/ propagating material (art. 9.3). These provisions directly relate to states ETOs, given that the ITPGRFA refers to the importance of international cooperation in its implementation and does not limit its scope to national jurisdictions.

\section{An integrated interpretation of human rights and environmental law}

Even though international human rights and environmental law have developed in a somewhat disconnected manner, recent years have seen important efforts aiming at bringing both together, including in the context of biodiversity. The creation, by the UN Human Rights Council, of a dedicated mandate on human rights and the environment has contributed to developing a better understanding of the interlinkages between human rights and environmental issues. ${ }^{1}$ This refers specifically to the understanding that the protection of the natural environment, including biodiversity, is indispensable for the effective enjoyment of a number of human rights. ${ }^{2}$ The former Special Rapporteur on Human Rights and the Environment has developed Framework Principles, which are based on his analysis of the interrelatedness between environmental issues and human rights and aim to 'facilitate the implementation of states' human rights obligations relating to the enjoyment of a safe, clean, healthy and sustainable environment' (Knox 2018, para. 7), including biodiversity. As his successor explains, these framework principles refer to three categories of state obligations, namely: 1) procedural obligations; 2) substantive obligations; and 3) special obligations towards those in vulnerable situations (Boyd 2020, para. 68). In the light of the fundamentally transboundary and global dimensions of biodiversity (see Section 2), these have all extraterritorial components. The Special Rapporteur has particular highlighted states' duty to ensure that activities within their jurisdiction or control do not cause harm to the environment or peoples of other states, as well as their obligation to cooperate internationally (ibid, paras. 73 and 74).

The procedural obligations identified by the Special Rapporteur are based on and reaffirm international standards regarding access to information and transparency; effective participation of rights holders; environmental, social and human rights impact assessments; access to justice and remedies; gender equality; as well as the protection of environmental human rights defenders. 'Each of these obligations applies to measures that affect biodiversity in ways that threaten the full enjoyment of the human rights that depend on its components' (Knox 2017, para. 28).

The substantial obligations are based on 'a general duty to protect biodiversity' (Knox 2017, para. 35) and require states to not violate the right to a healthy environment or other human rights related to healthy ecosystems and biodiversity through their own actions; to protect those rights from being violated by third parties, in particular businesses; and to establish, implement and enforce laws, policies and programs to fulfil these rights (Boyd 2020, para. 70). In this context, the framework principles emphasize in particular the need to rigorously apply the precautionary principle and to avoid discrimination and retrogressive measures.

Finally, the special obligations in the proposed Framework Principles refer to states' particular obligations towards marginalized and vulnerable groups, in particular indigenous peoples, peasants and other rural communities (Boyd 2020, para 72). As discusses above, these groups directly depend on functioning ecosystems and biodiversity and are therefore particularly affected by environmental harm in general, and biodiversity loss in particular. It is in this context that 
the adoption of the UN Declaration on the Rights of Indigenous Peoples (UNDRIP) as well as the UN Declaration on the Rights of Peasants and Other People Working in Rural Areas (UNDROP) are highly relevant. Both recognize the specific rights of rural people and clarify states' obligations in this regard, including concerning their rights to natural resources, land, seeds, biodiversity and a healthy environment (arts. 5, 17, 18, 19 and 20). Article 2 of the UNDROP specifically points to states' ETOs by underlining their duty to uphold their human rights obligations in the context of international agreements and international cooperation, as well as to regulate corporations and other non-state actors that they are in a position to regulate.

The two Declarations provide an opportunity for a more holistic reading of some key instruments of environmental law from a human rights perspective. The CBD, for instance, is built upon the premise that states have sovereignty over the biodiversity in their national territory. The question that arises from the recognition of specific rights of indigenous peoples and other rural people related to such resources by UNDRIP and UNDROP then is: what do states' sovereign responsibilities entail in terms of obligations to protect and guarantee communities' and people's rights? An important part of the answer to this question is that the effective protection of indigenous peoples' and other rural peoples' tenure, management, production and knowledge systems are key to addressing the rapid decline of biodiversity (Boyd 2020, para. 72). In this context, also specific normative guidance has been developed in the UN system on issues that are critical for the conservation of biodiversity. Instruments such as the Voluntary Guidelines to Support the Progressive Realization of the Right to Adequate Food in the Context of National Food Security, the Voluntary Guidelines on the Responsible Governance of Tenure of Land, Fisheries and Forests in the Context of National Food Security, as well as the Voluntary Guidelines for Securing Sustainable Small-Scale Fisheries in the Context of Food Security and Poverty Eradication, all refer to the need for sustainable management of natural and genetic resources and emphasize the importance of international cooperation in this regard. The Guidelines on the Responsible Governance of Tenure also contain specific paragraphs that clarify states' obligations to regulate and hold accountable corporations operating abroad (para 3.2) as well as to ensure that their own land-related investments abroad are consistent with human rights (para 12.15).

\section{Conclusion}

The rapid decline of biodiversity in the context of the deep ecological crisis that the world is facing has increased awareness about the complex relationships between human societies and their natural environment, and sparked efforts to bring together human rights and environmental law. It is now understood that a failure to comply with obligations to preserve biological diversity entails an elevated risk of human rights violations, and that addressing structural drivers of human rights violations critically contributes to the preservation of biodiversity.

It is important to stress that the cross-fertilization between the two spheres of law is already happening, especially in national and regional legislation and jurisprudence. ${ }^{3}$ Interesting lessons can be drawn from numerous examples of recognition and implementation efforts regarding the right to a healthy environment in national legislation (Boyd 2018, paras. $30 \mathrm{ff}$.). A particularly interesting case is a judgment of the Inter-American Court of Human Rights in February 2020, which recognizes the violations of the rights to food, water, a healthy environment and cultural identity of indigenous communities in Argentina. This judgment can be seen as a concrete example of integration of different sources of law, recognizing their interdependence and applying a holistic approach to human rights. ${ }^{4}$ Some countries have also recognized rights of nature in their legal frameworks. Such developments at national and regional level should inspire and guide further developments in international law. Indeed, the previous and current 
Special Rapporteurs on Human Rights and the Environment have been calling for the explicit recognition of a human right to a healthy environment by the UN General Assembly, of which biodiversity is one critical component.

Despite increasing awareness of the important nexus between human rights and biodiversity and the recognition of its transboundary and global dimensions, more work is needed to clarify and develop the concrete ETOs that arise for states in this context. The understanding of biodiversity as a 'global commons' is much less well established as compared to climate change. Even though the preamble of the CBD affirms that the conservation of biological diversity is a common concern of humankind, states have maintained a strong stance that the conservation of biodiversity is, primarily, an issue of national sovereignty. Increasing awareness on the critical importance of the impacts that states' acts and omissions can have on biodiversity, ecosystems and people beyond their national territories will be critical in order to advance in this regard and to address the current ecological crisis.

\section{Notes}

1. It should be noted that this work has been complementary to the work of the Special Rapporteur on the implications for human rights of the environmentally sound management and disposal of hazardous substances and wastes. See https://www.ohchr.org/EN/Issues/Environment/ToxicWastes/Pages/ SRToxicWastesIndex.aspx.

2. For more information, see: www.ohchr.org/EN/Issues/Environment/SREnvironment/Pages/SRenvironmentIndex.aspx.

3. Interesting resources are https://climate-laws.org/litigation_cases and http://climatecasechart.com/ non-us-climate-change-litigation. Although the focus lies on climate change, the cases compiled there are also relevant in the context of biodiversity.

4. For more information, see www.corteidh.or.cr/docs/comunicados/cp_24_2020_eng.pdf.

\section{References}

African Centre for Biodiversity (2020) 'Nature-based Solutions or Nature-based Seductions?', www.acbio. org.za/en/nature-based-solutions-or-nature-based-seductions [accessed 30 July 2021].

Berne Declaration (2014) 'Owning Seeds, Accessing Food. A Human Rights Impact Assessment of UPOV 1991', available at www.publiceye.ch/fileadmin/doc/Saatgut/2014_Public_Eye_Owning_Seed_-_ Accessing_Food_Report.pdf [accessed 30 July 2021].

Boyd, D. (2018) Report of the Special Rapporteur on the issue of human rights obligations relating to the enjoyment of a safe, clean, healthy and sustainable environment, available at https://undocs.org/ pdf?symbol=en/a/73/188 [accessed 30 July 2021].

(2020) 'Human Rights Depend on a Healthy Biosphere', Report of the UN Special Rapporteur on Human Rights and the Environment, available at https://undocs.org/A/75/161 [accessed 30 July 2021].

De Schutter, O. (2009) 'Seed Policies and the Right to Food: Enhancing Agrobiodiversity and Encouraging Innovation', Report of the Special Rapporteur on the Right to Food, available at https://undocs. org/A/64/170 [accessed 30 July 2021].

Ertör, I. and Ortega-Cerdà, M. (2018) 'The Expansion of Intensive Marine Aquaculture in Turkey: The Next-to-Last Commodity Frontier?', Journal of Agrarian Change, 1-24, available at https://onlinelibrary. wiley.com/doi/abs/10.1111/joac.12283 [accessed 30 July 2021].

ETC Group (2019) 'Plate Tech-Tonics. Mapping Corporate Power in Big Food', available at https://etcgroup.org/content/plate-tech-tonics [accessed 30 July 2021].

FAO (2005) 'Building on Gender, Agrobiodiversity and Local Knowledge', available at www.fao.org/3/ay5956e.pdf [accessed 30 July 2021]. 
FIAN International, Rede Social de Justiça e Direitos Humanos and Comissão Pastoral da Terra (2018) 'The Human and Environmental Cost of Land Business. The Case of MATOPIBA', htttp://bit.ly/ MATOPIBALandGrab [accessed 30 July 2021].

FIAN International/Transnational Institute/Focus on the Global South (2020) 'Rogue Capitalism and the Financialization of Territories and Nature', available at https://www.fian.org/files/files/Rogue_Capitalism_and_the_Financialization_of_Territories_and_Nature_(1).pdf [accessed 30 July 2021].

Global Network for the Right to Food and Nutrition/Global Convergence of Land and Water Struggles West Africa (2017) 'Business profits or diverse food systems? Threats to peasant seeds and implications in West Africa', available at http://www.fian.org/fileadmin/media/publications_2018/Reports_and_ guidelines/180329_FIAN_FFM_BurkinaFaso_EN_Web.pdf [accessed 30 July 2021].

Global Witness (2020) 'Defending Tomorrow. The climate crisis and threats against land and environmental defenders', www.globalwitness.org/en/campaigns/environmental-activists/defending-tomorrow [accessed 30 July 2021].

Guttal, S. and Chrek, S. (2016) 'An Overview of Large-Scale Investments in the Mekong Region. Focus on the Global South', available at http://bit.ly/LargeScaleInvestmentsMekong [accessed 30 July 2021].

Intergovernmental Science-Policy Platform on Biodiversity and Ecosystem Services (IPBES) (2019) Global Assessment Report on Biodiversity and Ecosystem Services. https://ipbes.net/global-assessment [accessed 30 July 2021].

Knox, J. (2017) 'Human Rights Obligations Relating to the Conservation and Sustainable Use of Biological Diversity', Report of the UN Special Rapporteur on Human Rights and the Environment, available at https://undocs.org/A/HRC/34/49 [accessed 30 July 2021].

(2018) Report of the Special Rapporteur on the Issue of Human Rights Obligations Relating to the Enjoyment of a Safe, Clean, Healthy and Sustainable Environment, available at https://undocs. org/A/HRC/37/59 [accessed 30 July 2021].

Tauli-Corpuz,V. (2016) 'Conservation Measures and their Impacts on Indigenous Peoples' Rights', Report of the UN Special Rapporteur on the Rights of Indigenous Peoples, available at https://undocs. org/A/71/229 [accessed 30 July 2021]. 